\title{
Uma ONG e suas práticas pedagógicas: uma contribuição para a educação não formal
}

Resumo: O objetivo deste texto é discutir acerca da Organização Não Governamental (ONG) como um potencial espaço educativo de Educação NãoFormal. Para auxiliar nessa discussão, aponto alguns resultados da pesquisa que desenvolvi no doutorado, em que analisei as práticas pedagógicas da ONG Grãos de Luz e Griô, localizada na cidade de Lençóis, no estado da Bahia. Constatei que esta instituição, possui algumas peculiaridades em sua abordagem pedagógica e isto, em minha análise, contribui para a necessidade de maior aprofundamento da discussão a respeito da educação não-formal.

Palavras-Chave: Educação Não Formal. Organização Não Governamental. Grãos de Luz e Griô.

\section{Primeiras Palavras}

A Educação Não Formal (ENF) tem sido apontada como um campo destacado nas pesquisas em Educação e, por esse motivo, tenho a intenção de apresentar neste artigo uma discussão que se refere aos espaços em que esse tipo de educação acontece e, desse modo, escolhi a ONG Grãos de Luz e Griô, na cidade de Lençóis, estado da Bahia, para tecer maiores considerações, pois foi nela que desenvolvi minha pesquisa de doutorado, buscando compreender suas práticas pedagógicas.

Para percorrer esse caminho, procurei o apoio teórico no campo da Educação Não-Formal (AFONSO, 1992; GOHN, 2000, 2001, 2004 e 2006; SIMSON et al, 2001; GARCIA, 2003, 2005), a fim de ampliar a discussão teórico-metodológica e por considerar que as ONG são espaços que realizam uma multiplicidade de projetos que envolvem temas de cunho educativo e que, por essa razão, têm contribuído em assessorias às Secretarias de Educação, Meio Ambiente e Saúde, muitas vezes a partir da oferta de cursos de formação continuada a professores da educação básica.

Atravessado por este embasamento, consegui ampliar as interpretações acerca da importância do espaço não formal como uma possibilidade significativa para o desenvolvimento de atividades fora da escola.

Para o escopo do presente artigo, procurei focar, em um primeiro momento, as características gerais da ENF e, logo em segui-

Marco Antonio Leandro Barzano

Universidade Estadual de Feira de Santana Departamento de Educação mbarzano@uol.com.br 
da, relaciono-as com as ONG. O terceiro momento refere-se ao caminho metodológico que percorri para o desenvolvimento da pesquisa. Por último, apresento a ONG Grãos de Luz e Griô, como um dos espaços educativos que me fez perceber algumas peculiaridades em suas práticas pedagógicas realizadas tanto no espaço das oficinas e cooperativas junto a crianças, adolescentes e jovens, que funcionam na sede da instituição, quanto em atividades realizadas nas comunidades, no envolvimento com as escolas.

\section{Educação Não Formal: Contribuindo para uma Caracterização}

Procurarei expor algumas conceituações acerca da Educação Não-Formal, sem a pretensão de esgotar as possibilidades de discussão no escopo desse texto, mas de tentar contribuir em seu plano teórico, como proposto, também, por Simson (2001, p. 910), quando afirma que: "[..] não existem muitas reflexões teóricas ou pesquisas empíricas que tratam do tema. Todavia, é possível elaborar uma fundamentação teórica para melhor evidenciar no que consiste a Educação não-formal".

Ao tratar da Sociologia da Educação Não-Escolar, Afonso (1992, p. 86-87), esclarece a caracterização entre educação formal, nãoformal e informal:

Por educação formal, entende-se o tipo de educação organizada com uma determinada sequência e proporcionada pelas escolas enquanto que a designação educação informal abrange todas as possibilidades educativas no decurso da vida do indivíduo, constituindo um processo permanente e não organizado. Por último, a Educação não-formal, embora obedeça também a uma estrutura e a uma organização (distintas, porém das escolares) e possa levar a uma certificação (mesmo que não seja essa a sua finalidade), diverge ainda da educação formal no que respeita a não fixação de tempos e locais e à flexibilidade na adaptação dos conteúdos de aprendizagem a cada grupo concreto.

Recorro a Gohn (2001), para compreender a trajetória histórica da Educação Não Formal, no Brasil. Para essa autora, até a década de 1980, este tipo de educação era um campo de pouca 
importância, pois as atenções eram sempre voltadas para a educação formal, institucionalizada, escolar.

Em um recente artigo, essa mesma autora considera importante demarcar as diferenças entre educação formal e não formal que, a seu ver, podem parecer extremamente simples, mas que não podem ser confundidas como simplificadoras, pois enquanto que na Educação Formal quem educa é o professor, na Educação Não Formal, "[...] o grande educador é o outro, aquele com quem interagimos ou nos integramos." (GOHN, 2006, p. 28, grifo da autora). As escolas são, portanto, os espaços territoriais da educação formal. Por outro 1ado, na Educação Não-Formal, "[..] os espaços educativos localizam-se em territórios que acompanham as trajetórias de vida dos grupos e indivíduos, fora das escolas, em locais informais, locais onde há processos interativos intencionais. (GOHN, 2006, p. 29)

Ao tratar da finalidade ou objetivos da Educação Formal e NãoFormal, a autora destaca que a primeira se detém ao ensino-aprendizagem de conteúdos historicamente sistematizados, normatizados por lei e com o objetivo de formar um indivíduo cidadão ativo, com uma variedade de habilidades e competências, capaz de desenvolver a criatividade, percepção e motricidade. Já o segundo tipo de educação, a não formal, "[...] capacita os indivíduos a se tornarem cidadãos do mundo, no mundo. Sua finalidade é abrir janelas de conhecimento sobre o mundo que circunda os indivíduos e suas relações sociais", ressaltando, ainda, que: "[...] a transmissão de informação e formação política e sociocultural é uma meta na Educação não-formal." (GOHN, 2006, p. 29-30)

Para Gohn (2001, p. 98), esse tipo de educação se caracteriza a partir de cinco dimensões, a saber: a primeira é a de aprendizagem política, que está relacionada com o processo de "conscientização dos indivíduos para compreensão de seus interesses e do meio social e da natureza que o cerca, por meio da participação em atividades grupais."

A segunda dimensão se refere à capacitação dos indivíduos para o trabalho, por meio da aprendizagem de habilidades e/ou desenvolvimento de potencialidades. Mesmo não concordando com o termo de educação comunitária, em virtude da carga ideológica do conceito de comunidade, a terceira dimensão é caracterizada pela autora, como a que está relacionada com "a aprendizagem e exercício de práticas que capacitam os indivíduos a se organiza- 
rem com objetivos comunitários, voltadas para a solução de problemas coletivos cotidianos." (GOHN, 2001, p. 99)

A autora comenta que a quarta dimensão está relacionada com a aprendizagem dos conteúdos da escolarização formal, escolar, porém, em formas e espaços diferenciados. A diferença, segundo ela, se refere à forma de abordagem, que é mais espontânea e "[...] as forças sociais organizadas de uma comunidade têm o poder de interferir na delimitação do conteúdo didático ministrado bem como estabelecer as finalidades a que se destinam àquelas práticas." (GOHN, 2001, p. 99) A quinta dimensão trata daquela em que, segundo esta autora, é desenvolvida na e pela mídia, em especial a eletrônica.

Os estudos investigativos sobre a Educação Não-Formal datam da década de 1970, nos Estados Unidos (GARCIA, 2003) e no Brasil, as experiências educativas em espaços não-formais também emergiram nesse período, mesclados com a educação popular e os movimentos populares que, à época, não possuíam prestígio acadêmico.

Com a intenção de contribuir para o embasamento da discussão de Educação Não Formal, Valéria Garcia (2005, p. 20) argumenta que

[...] criou-se um discurso de que o saber veiculado pela educação formal é crítico, por ser racional, científico, por ter referências e ser pautado no conhecimento científico. E o saber que não é da escola é ingênuo, por ser fundamentado na observação, na tradição, na oralidade e ser sensível aos argumentos da ciência, "comprobatória das verdades".

Diante de inúmeros projetos desenvolvidos em espaços nãoformais, torna-se necessário potencializar o papel da Educação Não-Formal, que muito tem contribuído na formação de cidadãos e que extrapolam os conhecimentos adquiridos na escola e é por esse argumento que tecerei maiores considerações referentes aos espaços educativos como as ONG.

\section{Organização não governamental: um lugar para se ensinar e aprender}

O termo Organização Não-Governamental, segundo SchererWarren (1998, p. 162), vem dos países do Norte, "[...] referindo-se 
a entidades ou agências de cooperação financeira a projetos desenvolvimentistas ou assistencialistas, em favor de populações desprivilegiadas do Primeiro e do Terceiro Mundo". Com a intenção de fazer um breve percurso histórico, recorro a Gohn (2000) que, mesmo afirmando que alguns autores datam o surgimento das ONG no Brasil desde a época da Colônia, acredita "[...] que as modernas ONG são produtos do século XX, quando o Estado passa a ter papel central na vida das nações" (SCHERER-WARREN, 1998, p. 53) e, fazendo um recorte espaço-temporal, diz que "a [...] maior parte das ONG's da América Latina surgiu após os anos 70". (SCHERER-WARREN, 1998, p. 56)

A mesma autora esclarece que o surgimento destas instituições ocorre com a diminuição dos movimentos sociais organizados. (GOHN, 2000, p.11) Em virtude da Eco-92, as ONG, principalmente as que estavam mais voltadas para a temática ambiental, tiveram um crescimento significativo e isso se deveu, também, por causa dos movimentos populares de bairro, principalmente os periféricos, que possuem graves problemas relacionados com córregos a céu aberto, ausência ou coleta irregular do lixo, focos de várias infecções, má distribuição de água potável, entre outros. (GOHN, 2004)

Assim, houve a necessidade de uma sistematização com os tipos de ONG atuando no Brasil nos anos 90: as caritativas, voltadas para a assistência a partir de categorias específicas como: menor, mulher e velhos; as desenvolvimentistas, que são aquelas em que o Meio Ambiente está inserido; as cidadãs, voltadas para a reivindicação dos direitos da cidadania, como a Anistia Internacional, que é uma ONG dedicada aos direitos humanos e as ambientalistas, que possuem premissas do desenvolvimento autossustentável e da cooperação internacional. (GOHN, 2000)

Considero, portanto, que nos últimos anos, as ONG não são apenas locais de assistência à população economicamente menos favorecida. Mais que isto, elas têm servido como polos difusores de conhecimentos, que participam tanto na formação de crianças, adolescentes e jovens, como na formação continuada de professores, por exemplo, como ocorre com a ONG Grãos de Luz e Griô, localizada na cidade de Lençóis, no estado da Bahia, e que foi objeto de minha pesquisa de doutorado.

A partir da contribuição do quadro teórico apresentado e dos resultados obtidos em minha tese, reconheço nas ONG, um espa- 
(1) Ressalto o campo da Educação, pois a maioria das publicações de pesquisas que se referem às $\mathrm{ONC}$ estão inseridas no campo das Ciências Sociais e Economia. ço em que encontro uma prática educativa que leva em consideração uma pluralidade de saberes; um local que busca a construção de um corpo de conhecimentos que ensina conteúdos/temas diferentes da escola, pois não se preocupa com a certificação e com a hierarquização das séries e disciplinas, por exemplo.

Passarei a abordar com mais detalhes as práticas pedagógicas da ONG Grãos de Luz e Griô, com o objetivo de compartilhar os saberes produzidos neste espaço educativo e, com isso, pretendo contribuir para que ele e outras ONG sejam mais investigados, percebidos pelos professores e pesquisadores do campo da Educação ${ }^{1}$. Antes, porém, apresentarei o caminho metodológico que percorri para o desenvolvimento da pesquisa.

\section{Caminho metodológico}

A feitura da pesquisa de doutorado foi marcada por inúmeras provocações e uma delas quero apontar neste artigo que se refere à uma ruptura: tentar "colocar em prática" novas sensações de olhar e fazer pesquisa. De escapar do campo epistêmico estruturalista e experimentar aquele outro: a vertente pós-estruturalista na qual, a meu ver, o aspecto cultural - que é potente na pesquisa que desenvolvi no doutorado - tem condições de ganhar mais força e coloca a cultura com outro significado, assumindo "uma função de importância sem igual no que diz respeito à estrutura e organização da sociedade moderna tardia." (HALL, 1997, p. 17)

Ao fazer a opção de realizar uma pesquisa inspirada na vertente pós-estruturalista, percebi que, necessariamente, é preciso escolher, colocar ao avesso tudo aquilo que tranquiliza, que estabiliza. E essa foi a minha tentativa, apostando muito mais nas invenções e escapando das certezas.

Para início de conversa, anuncio que as estratégias metodológicas que elaborei para a realização da pesquisa aconteceram à medida que a própria pesquisa se desenvolveu. A princípio, o material que eu dispunha era constituído de vídeos e relatórios e, a partir deles, percebi que não eram suficientes para a realização do trabalho investigativo. Diante disto, fui a Lençóis, entrevistar professores e alunos e observar as práticas pedagógicas da ONG.

Como comentei anteriormente, os materiais que consegui com a ONG para uma primeira aproximação do que era abordado 
em suas práticas pedagógicas foram os vídeos e os relatórios anuais e passo a nomeá-los de artefatos culturais que, mais tarde, foram acrescidos do livro Pedagogia Griô: a reinvenção da roda da vida, de autoria da coordenadora pedagógica da ONG e o documentário Sou Negro, que foi distribuído juntamente com o livro, em março de 2006.

Com os primeiros artefatos em mãos, procurei fazer uma primeira leitura para ter contato com aquela ONG. Quais eram as temáticas abordadas? Qual o público atendido? Quais as oficinas e cooperativas que funcionavam? Essas foram as primeiras perguntas que me impulsionaram no encontro com aquele material. Deixei-me entregar pelos discursos ali produzidos, fazendo as primeiras seleções daquilo que, naquele momento, me parecia interessante para pensar na pesquisa, recorrer a referências bibliográficas e ampliar a discussão teórico-metodológica.

Antes de ir a Lençóis, fui ao lançamento do livro e documentário que mencionei anteriormente, ocorrido em março de 2006, na cidade de São Paulo, e pude fazer, também, uma leitura dos discursos que constituem estes artefatos.

Para minha ida a Lençóis, já sabia que queria fazer algumas entrevistas, fotografar e observar o cotidiano das práticas pedagógicas. Levava um questionário semiestruturado, fitas cassete, um minigravador, uma câmara fotográfica digital, pilhas recarregáveis, um caderno de campo e muita vontade de enveredar naquele outro lado da pesquisa, talvez, digamos, o mais prático. Era a vontade de experimentar fazer uma pesquisa que não tivesse que seguir muita fixidez metodológica.

Meus registros no caderno de campo iniciaram desde o momento em que cheguei naquele dia 8 de maio de 2006. Uma tarde com "uma temperatura agradável: nem frio, nem calor. Soube que tinha chovido bastante. O rio encheu muito. As águas estavam transbordando em várias ruas" ${ }^{2}$. Transbordamento era a palavra-chave não só por conta da água da chuva nos rios, mas a expectativa daquilo que estava por vir, com minhas ideias e imaginações. Transbordamento de água que desfazia as bordas do caminho.

Com a intenção de compreender as práticas pedagógicas da ONG Grãos de Luz e Griô (GLG), participei de quase ${ }^{3}$ todas as oficinas e cooperativas ${ }^{4}$. As oficinas eram: papel reciclado e retaThos; brinquedos e brincadeiras; arte e identidade; música e tradição oral. As cooperativas eram: turismo de base comunitária - grupo
(2) Anotação do diário de campo, no dia 8 de maio de 2006.

(3) Digo quase todas porque não participei de algumas delas, pois as entrevistas marcadas coincidiam com o mesmo horário.

(4) As oficinas são para as crianças e adolescentes. As cooperativas são para os jovens. As faixas etárias podem variar em uma situação ou outra, dependendo do tempo de envolvimento daquele aluno com a ONG, por exemplo. Geralmente, as crianças e adolescentes têm entre 7 e 15 anos e os jovens a partir de 16 anos. 
(5) Diante de um expressivo número de alunos matriculados na ONG, tive que selecionar apenas alguns deles para conversar. Os alunos que considero os "mais interessantes" foram aqueles que participavam há mais tempo das atividades da ONG, ou seja, os que já conheciam a proposta pedagógica por vários anos e haviam participado de um maior número de oficinas e cooperativas.; calumbé; música e tradição oral; cultura digital; papel reciclado e retalhos. Com exceção da oficina de papel reciclado e retalhos, todas as outras funcionavam no período vespertino e todas as cooperativas funcionavam no período matutino.

Minha participação na observação do cotidiano das práticas pedagógicas era diária e eu ficava imerso naquelas vivências, algumas vezes, inclusive, lanchando com os alunos no horário da merenda. Para mim, aquele era um momento importante para minhas leituras dos discursos que se estabeleciam entre aquelas crianças e jovens: suas aspirações, seus desejos, relações interpessoais, ou seja, era o momento do intervalo, assim como o recreio na escola, o tempo de um outro - ou até mais um momento pedagógico, em que circulam saberes que, muitas vezes, passam despercebidos, mas que são ricos de peculiaridades.

E foi dessa maneira, embrenhado naquele cotidiano, que conheci aquele público de estudantes e, também, selecionei aqueles que considerei os que poderiam ser interessantes para conversar $^{5}$ e que passo a comentar com maior riqueza de detalhes, no escopo deste artigo.

\section{O Encontro com a cidade de lençóis: pistas para o desenvolvimento da pesquisa em educação não formal}

Interessado em pesquisar como se estabelece a prática pedagógica nesse contexto não-formal, iniciei a investigação na ONG Grãos de Luz e Griô, situada na cidade de Lençóis, Chapada Diamantina, no estado da Bahia. Essa ONG apresenta uma proposta educativa que possibilita às crianças e jovens que atuam neste espaço, entrarem em contato com saberes da cultura, da tradição ancestral, da identidade e que, provavelmente, não terão essa discussão abordada na sala de aula.

Antes de apresentar a discussão referente às práticas pedagógicas da ONG, pretendo tecer algumas considerações relacionadas ao contexto em que este espaço educativo se encontra, pois sua sede localiza-se na cidade de Lençóis, que é considerada o portal do Parque Nacional da Chapada Diamantina, com marcas históricas relacionadas ao garimpo de diamantes; à exuberância de uma rica biodiversidade e, nos últimos anos, tem recebido a visita de turistas do Brasil e exterior à procura de um "turismo ecológico", 
motivados pela ideia midiática de que a cidade possui uma beleza paisagística caracterizada por suas matas e cachoeiras.

E foi este imaginário "paradisíaco" que me mobilizou a conhecer a cidade, em 2002. Como professor de Prática de Ensino de Ciências e Biologia, outro fator me carregou para este lugar foi o fato de a Universidade Estadual de Feira de Santana (UEFS) ter ali um campus avançado. Como professor desta instituição, consegui nesta cidade o lugar ideal para a realização do planejamento de aula que contemplava uma abordagem da Educação Não Formal, junto aos licenciandos do curso de Ciências Biológicas. Com o interesse em desenvolver um projeto interdisciplinar, procurei a companhia de um professor de Prática de Ensino de História da mesma instituição e elegemos a história ambiental como eixo norteador para nosso trabalho pedagógico. Essa ideia foi mobilizada pelo fato de constatar que, geralmente, o currículo das disciplinas pedagógicas privilegia apenas o enfoque escolar deixando uma lacuna no que se refere à Educação Não Formal.

Professor, turista, estrangeiro, quiçá um buscador. Foi desta maneira que cheguei a Lençóis. Comungo com Ítalo Calvino (2005, p. 14) que a cidade não é constituída tão somente pelos prédios, escadas, lâminas de zinco que recobrem os tetos, enfim, sua estrutura, como nos ensinam, mas "[...] das relações entre medidas de seu espaço e os acontecimentos do passado", e foi por isso que pretendi conhecer a cidade de Lençóis impregnada de sua biodiversidade, suas culturas, mitos, sabedorias, uma cidade que não conta o seu passado, porque ela o contém. (CALVINO, 2005, p. 14)

Passei pela cidade através de meu sonho e encarei-a como uma cidade invisível, rica em memória, pulsante em desejo, repleta de símbolos, lisa, estriada, delgada. A cidade que não é apenas um conceito geográfico e se torna símbolo daquilo que encontrei nos desvios percorridos.

Minha primeira ideia era "achar" muitas coisas e falar sobre elas, como a rica biodiversidade ainda pouco conhecida do ponto de vista histórico e biológico. Conhecer aquele lugar foi compreender o potencial naturalístico que ele dispunha para que eu pudesse abordar em minhas aulas, junto aos alunos de Licenciatura em Ciências Biológicas e que a partir de 2004 se transformou em minha pesquisa de doutorado na Faculdade de Educação da Unicamp.

A partir de 2005, em visita à cidade para a realização da pesquisa, conheci uma outra Lençóis, que não era marcada por aqui- 
(6) Panôs são estandartes de tecido com algumas figuras e, geralmente, são expostos em paredes. lo que já era considerado por sua rica biodiversidade. Fui tomado pelo estranhamento quando visitei, em janeiro daquele ano, a exposição Griô, a tradição viva, no Mercado Cultural desta cidade, que continha os materiais produzidos pelos alunos da Grãos de Luz e Griô. Considerei que estava diante de um rico acervo para a pesquisa porque ali estavam expostos nos objetos, um conjunto simbólico dos produtos que remetiam à africanidade.

Desestabilidade. Invisibilidade. Visitar uma cidade que representa o eixo da Chapada Diamantina, o que se espera tão visivelmente exposto? Fotografias de árvores, animais e cachoeiras? Exposição de diamantes e objetos utilizados no garimpo? Não! Panôs ${ }^{6}$ de orixás. Quadros pintados com figuras de pessoas negras. Materiais de papel reciclado com desenhos da cultura local, todos confeccionados pelos alunos da ONG Grãos de Luz e Griô e que estavam expostos como culminância dos trabalhos desenvolvidos nas oficinas e cooperativas, mas que para mim, trazia um outro significado: o de mostrar as características daquela cidade e que muitas vezes encontravam-se rasuradas ou até mesmo apagadas.

Após esse aspecto panorâmico de minha entrada na cidade, apresentarei a ONG Grãos de Luz e Griô e sua proposta pedagógica junto a crianças, adolescentes e jovens em oficinas e cooperativas e, também, com professores da rede municipal de educação de Lençóis.

\section{Grãos de Luz e Griô: Seu histórico e suas práticas pedagógicas}

Em 1993, na cidade de Lençóis, houve a iniciativa de lideranças femininas na produção e distribuição de sopa para as crianças de baixa renda de um bairro periférico. No mesmo período, havia um projeto de horta comunitária desenvolvido por crianças e adolescentes. Essas iniciativas foram agregadas a um projeto educativo de uma brasileira que residia na Suíça que, ao tomar conhecimento dessas atividades em Lençóis, reuniu um grupo de amigos daquele país para a realização de tal empreitada. Para seu funcionamento era preciso ter um prédio e as madres da igreja católica da cidade cederam esse espaço, colaborando com atividades de artesanato e reforço escolar.

Em 1997, houve a institucionalização daquele projeto, principalmente pela necessidade de estabelecer as parcerias de apoios 
financeiros. A partir de 1998, as atividades pedagógicas passaram a ter um nome: Oficinas Grãos de Luz e de 1999 a 2002 o Grãos de Luz passou a presidir o Conselho Municipal de Direitos da Criança e do Adolescente. (PACHECO, 2006)

Durante o ano de 1999 foi o momento que se estabeleceu a parceria entre a ONG e a Secretaria Municipal de Educação de Lençóis $(\mathrm{SMEL})^{7}$. A primeira iniciativa desta Secretaria foi a solicitação da participação da ONG junto aos professores da rede municipal para a elaboração de um projeto pedagógico e, para isto, a coordenação pedagógica da ONG apresentou uma proposta de trabalho que incluiu a invenção da figura de um velho africano: o griô. Desde então, foi criado o projeto griô.

Além das atividades que foram desenvolvidas em seu espaço educativo, através de oficinas e cooperativas, a Grãos de Luz passou a atuar nas escolas e comunidades, com o projeto griô e ampliou suas parcerias, ganhando visibilidade nacional na mídia impressa e televisiva, anunciando a realização de suas práticas pedagógicas. Foi a partir deste ano que a ONG passou a ser nomeada Grãos de Luz e Griô.

No ano de 2002, esta instituição ampliou seu raio de atuação para 15 municípios da Chapada Diamantina desenvolvendo, principalmente, a atividade de caminhada do velho griô que consistia em sua ida às comunidades e escolas para contar histórias. Foi neste ano que conheci o espaço educativo da Grãos de Luz e Griô e fui informado de que anualmente era trabalhado um tema gerador e, naquele ano, a Água tinha sido a temática abordada.

Dentre várias atividades que aconteceram no ano de 2002, houve a realização do Prêmio Mãe Água, que possibilitou aos professores desenvolverem projetos pedagógicos relacionados com este tema. Os alunos realizaram levantamento da situação da água na cidade e discutiram possíveis soluções, além de fazerem limpeza às margens dos rios, bem como a construção de placas com frases ecológicas e a elaboração de uma carta que fora enviada ao prefeito acerca dos problemas encontrados e da solicitação de providências que deveriam ser tomadas, destacando a aquisição de lixeiras e limpeza das ruas.

Além desse projeto pedagógico, os alunos desenvolveram outras atividades de intervenção ambiental, entrevistando, fotografando e observando gestuais do trabalho de lavadeiras e garimpeiros. Com esse material, que incluía em seus registros as
(7) A parceria se estabeleceu com o oferecimento de atividades pedagógicas pela ONG, e a contrapartida da Secretaria Municipal de Educação de Lençóis era através de apoio na infraestrutura do espaço educativo daquela instituição, como por exemplo, a merenda distribuída aos alunos. 
crenças, mitos, danças, foram confeccionados os panôs que, além de demonstrarem as características da cultura local, eram comercializados e propiciavam a visibilidade dos trabalhos pedagógicos da ONG. As apresentações das peças teatrais Mãe Água e Três Vidas e um Rio foram, também, as culminâncias do projeto pedagógico de 2002, realizado pela ONG nas escolas.

Após o lançamento do edital que regulamentava o concurso do prêmio Mãe Água, organizado pela instituição, os professores da rede de ensino realizaram, durante o período de dois meses, a confecção de diversos materiais como: maquetes, livros e revistas artesanais, painéis de material reciclado e fotografias.

Considero que essa tenha sido uma das maneiras de ela ter conseguido obter visibilidade não só na cidade de Lençóis, como também na Chapada Diamantina. Outra maneira foi na realização de atividades culturais em vários pontos da região e isso fez com que as autoridades locais começassem a apostar em uma parceria mais consolidada, como afirmou o Secretário de Educação, daquela época, João Bina: "[....] nós confiamos na competência do Grãos de Luz, por isso nos unimos para concretizar o sonho de regulamentar um programa de incentivo ao professor municipal e dar continuidade à parceria". (RELATÓRIO..., 2003, 6)

No que diz respeito à aproximação com a Secretaria Municipal, é importante mencionar que a ONG começa a enunciar uma prática discursiva que coloca as atividades desenvolvidas por ela como o que vou chamar aqui de ruptura epistêmica, ou seja, há a necessidade dos professores fazerem, primeiramente, uma ruptura com o ensino tradicional que até então era considerado como o recorrente nas práticas escolares e que a proposta pedagógica da ONG considerava como ineficaz, como foi anunciado por diversas vezes nos materiais impressos, audiovisuais e até mesmo nas entrevistas quando realizei a coleta de dados.

O fato de a ONG participar de atividades junto à SMEL a partir do oferecimento de curso de capacitação é uma maneira, também, de conseguir destaque para a divulgação e ampliação do seu trabalho, através da inclusão de temas relacionados com o projeto griô, seja no currículo das escolas, criando possibilidades de engendramento de práticas pedagógicas, ou na sua inserção junto às comunidades.

Desta maneira a ONG pôde ganhar mais visibilidade da população local e autoridades políticas e isto tomou uma dimensão 
maior, quando ela era procurada para anunciar sua proposta pedagógica em vários programas da mídia televisiva e impressa como Tv Cultura, Tv Globo, Folha de São Paulo, O Estado de São Paulo, A Tarde, Jornal do Commercio, entre outros.

Considero que até o ano de 2002 a Grãos de Luz e Griô enfatizou a perspectiva ambiental em suas atividades pedagógicas e isto não se sucedeu tão fortemente nos anos seguintes. A meu ver, isto se deveu aos novos interesses que a ONG passou a estabelecer, principalmente aqueles que se referem aos editais em que ela inscrevia seus projetos e estes se vinculavam, principalmente, a financiamentos relacionados à cultura.

Expressaram-se nas práticas pedagógicas que observei e li/ouvi nos artefatos analisados, o desejo de a ONG não ter mais o meio ambiente como eixo de suas atividades. Percebi que isto ficou circunscrito às oficinas e cooperativas de reciclagem de papel. Saliento, portanto, que a ONG nunca se denominou ou sequer associou suas atividades com a temática ambiental, nem tampouco foi nomeada como uma ONG ambientalista. Mas imagino que isso pode não ter ocorrido devido ao fato de esta instituição não ter feito parceria ou participado de editais que se associavam ao meio ambiente. Talvez isto tenha contribuído para que a ONG não inventasse uma "Pedagogia Ambiental", como aconteceu com a abordagem cultural que ganhou centralidade em todas as práticas pedagógicas da ONG, incluindo as parcerias externas realizadas junto aos professores da rede municipal de Lençóis.

Nos anos de 2004 e 2005, o tema gerador abordado pela ONG junto às escolas foi Griô, a tradição viva e, desse modo, a cultura ganhou a centralidade nas abordagens pedagógicas desta instituição. Foi a partir deste período que a ONG definitivamente deslocou a abordagem ambiental e passou a focar a cultura negra, a ancestralidade e a cultura local e, desde então, essa abordagem se fixou de tal modo que ainda hoje os títulos dos projetos são diferentes, mas em todos eles foi a cultura que ganhou força e isto eu considero que tenha sido referente às parcerias que a ONG se associou, principalmente ao Ministério da Cultura, quando teve a aprovação de um projeto referente ao Ponto de Cultura.

Retomando as especificações da ONG, quero salientar que em 2006, quando visitei a ONG para a realização das visitas, observação e entrevistas, esta instituição concentrava suas atividades pedagógicas em sua sede, junto a crianças, adolescentes e 
(8) Especificamente, o nível de instrução dos dirigentes (presidente e coordenadora de projetos) é nível superior completo.

(9) Como essa região africana foi colonizada pela França, a palavra é de origem francesa. O feminino é griote. Na Língua Portuguesa, escreve-se griô para ambos os sexos e esta será a maneira que utilizarei em todo o texto da tese. jovens em oficinas e cooperativas. No turno da manhã funcionavam as cooperativas e na parte da tarde, as oficinas, sempre de terça a sexta-feira, pois às segundas-feiras eram reservadas para reuniões da equipe de professores e funcionários.

Em relação à organização, a ONG possui um presidente, uma tesoureira, o conselho fiscal e uma coordenadora de projetos. Há, ainda, uma equipe de coordenadores que tratam da parte pedagógica das oficinas e cooperativas, bem como de uma equipe de consultoras pedagógicas. Os graus de instrução destes profissionais são variados: desde a que possui o ensino fundamental completo a doutora em educação ${ }^{8}$.

A ONG nomeia de "Roda de Solidariedade do Grãos de Luz e Griô", os órgãos financiadores, que se distribuem em públicos e privados, como Ministério da Cultura, Secretaria de Estado de Educação da Bahia, Secretaria Municipal de Educação de Lençóis, IPHAN, UNESCO, Hotel Canto das Águas, Hotel Lençóis Rede Globo (Criança Esperança), Action for Brazil's Children, Graines de Lumiére Amis Europeens, entre outros.

\section{Griôs Africanos:} Uma inspiração para as práticas pedagógicas

No noroeste da África, na região do Mali, vivem velhos que percorrem aldeias, contando histórias, cantando músicas, declamando poesias ou até mesmo mediando desavenças entre as grandes famílias e são chamados de griots ${ }^{9}$. São trovadores ou menestréis, grandes sábios, que transmitem sabedoria da tradição oral.

Para Hampaté Bâ (1982, p. 202), os griôs se classificam em três categorias:

- Músicos: que tocam qualquer instrumento (monocórdio, guitarra, cora, tantã, etc) e, geralmente, são grandes cantores, que compõem, preservam e transmitem a música antiga.

- Embaixadores e Cortesãos: que são responsáveis em mediar as possíveis desavenças que ocorrem entre famílias. Eles estão sempre ligados a uma família nobre ou real. Também são encarregados de algumas funções, como, por exemplo, fazer união matrimonial: quando um jovem nobre 
necessita revelar seu amor a uma jovem nobre, ele solicitará a um griô para que este se encarregue de ser o portavoz do seu sentimento.

- Genealogistas, historiadores ou poetas (que podem ser os três ao mesmo tempo): são os contadores de histórias, viajantes e não estão, necessariamente, ligados a uma família.

Pelas observações e análises que fiz na pesquisa com a ONG Grãos de Luz e Griô, percebi que a música serviu de forte inspiração para esta instituição e por esta razão o griô personificado, que percorria as comunidades lençoenses se aproximava com mais intensidade da imbricação entre o griô músico e o genealogista. Na África, a música está presente desde as mais simples apresentações dos griôs, como também nas cerimônias ou danças rituais, geralmente tocadas por iniciados.

Há uma maneira específica de a música ser abordada que é pela tradição africana, inspirada nos velhos griôs, em que o foco é a cultura local e isto se diferencia de alguns grupos musicais ${ }^{10}$ majoritariamente representados por afrodescendentes, que possuem sua marca na música engajada, naquela que procura recuperar a imagem positiva do negro e para isto utilizam algumas táticas como, por exemplo, a composição de letras em que a África ganha centralidade, mostrando a valorização da raça negra, como ocorreu, principalmente, desde da década de 1970, com os blocos afro no estado da Bahia.

Mesmo que a ONG também utilize a música em suas práticas pedagógicas com o objetivo de valorização do negro, a instituição não recorre às letras de músicas dos grupos afro de Salvador, mas fazem um levantamento da cultura local e aprendem as músicas cantadas pelos velhos da cidade e que geralmente são cantigas entoadas por estas pessoas no momento do trabalho com a agricultura, quando estes "pisam" o milho e a mandioca no pilão, por exemplo.

Observei que além dessas músicas/cantigas "do campo" os alunos também produziam suas próprias canções; aprendiam com os velhos, a tocar vários instrumentos. Dois outros aspectos me chamaram a atenção quando entrevistei os alunos: o primeiro foi o fato de eles afirmarem que gostaram de aprender as canções entoadas pelos velhos das comunidades e o outro foi o destaque dado ao hip hop, que foi estimulado pelos coordenadores da ONG.
(10) Os grupos musicais, aos quais me refiro, são, principalmente, aqueles da Cidade de Salvador, e que são conhecidos internacionalmente como o llê Ayiê e o Olodum. 
Observei mais nitidamente esses dois momentos musicais marcados por duas gerações: a dos velhos e dos jovens. Marcados, também, por diferentes estilos que são marginalizados pela sociedade. O primeiro por valorizar a música do campo, da cultura popular e o segundo por ser associado à classe popular onde, geralmente, estão inseridos os negros e pessoas de baixa renda.

Stuart Hall (2003), ao discutir sobre o negro na cultura negra, lembra-nos que a vida cultural, sobretudo no Ocidente e em outras partes, tem sido transformada em nossa época pelas vozes das margens. As estratégias pedagógicas utilizadas pela ONG fizeramme perceber que ela conseguiu recuperar a valorização do "popular", ou seja, fazer com que os alunos compreendam o significado do popular e escapem do preconceito, geralmente a ele associado.

\section{E a ONG vira uma pedagogia}

Diante da investigação realizada, afirmo que a ONG Grãos de Luz e Griô estabelece uma pedagogia - que nomeia de griô - a partir da caminhada do velho griô, nas escolas e comunidades de Lençóis. Assim, é o griô que surge e inventa uma pedagogia. O prêmio Itaú-UNICEF, recebido em dezembro de 2003, foi o ato inaugural para desencadear as estratégias de ação, que a ONG denomina de "modelo de ação pedagógica", assim distribuídas. (PACHECO, 2006, p. 28)

1. Oficinas e cooperativas com crianças, adolescentes, jovens e suas famílias;

2. Caminhada do Velho Griô com griôs e grupos culturais nas escolas e comunidades;

3. Integração da tradição oral no currículo da educação municipal, com educadores municipais e atores de todas as idades do sistema municipal de ensino; e

4. A roda da vida e das idades, com todos os participantes, em diálogos com parceiros dos três setores sociais, conselhos municipais, estaduais e federais, universidades, projetos, programas e políticas do país e do mundo.

Além dessas estratégias operacionais, é necessário destacar que a Pedagogia Griô fundamenta-se nos princípios filosóficos, políticos e pedagógicos que se remetem, principalmente, ao pen- 
samento de Paulo Freire, enfocando a pedagogia dialógica; a educação biocêntrica e a educação afro-brasileira. (PACHECO, 2006, p. 84) No amálgama dessas três inspirações, a Pedagogia Griô passa a ser definida como uma pedagogia da "vivência afetiva e cultural que facilita o diálogo entre a tradição oral, o ensino formal e o projeto de vida, para a construção do conhecimento total, o fortalecimento da identidade e a celebração da vida."

Tanto o discurso da pedagogia freireana quanto o da educação biocêntrica foram definidos desde o período em que a ONG só funcionava em sua sede, e que priorizava o trabalho pedagógico nas oficinas e cooperativas. Já a proposta de inclusão da educação afro-brasileira, na Pedagogia Griô, surge com maior força a partir do prêmio Itaú-UNICEF, que a ONG foi contemplada e que ocorreu em dezembro de 2003, e priorizava a necessidade de parceria junto às escolas.

Com a inspiração freireana de abordar temas que pudessem contemplar a realidade do aluno, a Pedagogia Griô é inserida na reestruturação curricular das escolas do município de Lençóis, apoiada, ainda, na alteração da Lei no 9.394/1996, de diretrizes e bases da educação, que contempla o Decreto-lei $n^{\circ} 10.639 / 2003$, que torna obrigatório aos estabelecimentos de ensino públicos e privados a inclusão, em seus currículos, do ensino sobre História e Cultura Afro-Brasileira, permeado em diferentes disciplinas, como História, Literatura e Artes.

Neste momento, a Pedagogia Griô cria possibilidades de escolher a cultura negra tanto para se "trabalhar com a realidade", com temas geradores, mas mais que isso: de se amparar em uma lei que pode ser considerada como inclusiva e reparadora. Desse modo, o griô é inventado e, ao mesmo tempo é fabricado junto com a pedagogia, conferindo uma maior noção de uma pedagogia progressista.

Pedagogia que surge com semelhanças a tantas outras que foram inventadas pelo sistema educacional brasileiro e que nos incita às mesmas perguntas, de natureza curricular: que saberes são transmitidos por essa pedagogia? Há distinção entre formal e não-formal? Pelo sim, pelo não, por quê? É a ONG que decide os temas que os professores devem ensinar? Independente dessa decisão, que critérios são estabelecidos?

A figura do griô é o ponto de interseção entre os dois momentos da ONG, aquele em que as atividades pedagógicas eram 
desenvolvidas tão somente na sede da instituição e que, portanto, era apenas uma ONG e aquele que vai acontecer tanto neste espaço educativo quanto nas escolas e nas comunidades, como Pedagogia Griô.

\section{Palavras finais}

O texto aqui apresentado buscou destacar e aprofundar o conceito de educação não formal, amparado por uma fundamentação teórica de diferentes autores. Conclui-se que é um conceito que, mesmo sendo pesquisado desde a década de 1970, ainda carece de maiores investigações já que os espaços educativos são pulverizados em diferentes instituições, com atendimento a diferentes públicos e faixa etária. As ONG, que são representantes dos movimentos sociais e desenvolvem inúmeros projetos relacionados com uma multiplicidade de temas, também são importantes exemplos, seja nas disciplinas de prática de ensino dos cursos de licenciatura como vimos no presente texto. Com a intenção de tecer maiores considerações acerca da Educação Não Formal, apresentei a análise de práticas pedagógicas desenvolvidas na ONG Grãos de Luz e Griô, que foi objeto de pesquisa da minha tese de doutorado.

Em virtude da inserção das práticas pedagógicas desenvolvidas pela ONG, a Grãos de Luz e Griô estabelece uma pedagogia e a nomeia de griô a partir da caminhada do velho griô, nas escolas e comunidades de Lençóis. Desse modo, é o griô que surge e inventa uma pedagogia, com uma proposta de ruptura com o ensino tradicional ainda vigente nas escolas.

Ao entrar em contato com a Grãos de Luz e Griô, percebi que a cidade de Lençóis passa a ser marcada não apenas por dois fatores como a extração de diamantes e pelo turismo, geralmente abordados em várias pesquisas. Defendo posição de que há um terceiro fator que é a presença do griô, daquele que guarda saberes da cultura local e os transmite às novas gerações. A cidade de Lençóis passa a ter uma nova referência com a inserção do griô e isto confere a diferença neste lugar, pois este personagem e até mesmo aqueles velhos da cidade, que a ONG também nomeia de griôs e apostam na tradição oral em pleno século XXI. Este é o grande salto que a ONG consegue e que marca seu diferencial como uma prática pedagógica de Educação Não Formal. 
A NGO and their pedagogical practices: an addition for non-formal education

\begin{abstract}
The current scientific article has main aim to discuss Grãos de Luz and Griô No Governamental Organization (NGO) pedagogical practices. For supporting my argument I have pointed out some results from this research performed on Phd course. The NGO in question is located in Lençóis City, Bahia State, Brazil and from data analysis some peculiarities on its pedagogical approachment, specific of non-formal education system I have noted, as well. Keywords: Non-formal education. No Governamental Organization. Grãos de Luz and Griô.
\end{abstract}

\title{
Referências
}

AFONSO, Almerindo Janela. Sociologia da educação não-escolar: reactualizar um objecto ou construir uma nova problemática? In: ESTEVES, J.; STOER, S.R. (Org.). A sociologia na escola: professores, educação e desenvolvimento. Porto; Afrontamento, 1992.

CALVINO, Ítalo. As cidades invisíveis. São Paulo: Companhia das Letras, 2005.

GARCIA, Valéria A. Educação não-formal: memórias, patrimônio e meio ambiente. In: PARK, Margareth B. (Org.). Formação e educadores: memórias, patrimônio e meio ambiente. Campinas: Mercado de Letras, 2003.

. Um sobrevôo: o conceito de educação não-formal. In:

PARK, Margareth B.; FERNANDES, Renata S. (Org.). Educação nãoformal: contextos, percursos e sujeitos. Campinas, SP: Holambra, 2005.

GOHN, Maria da Glória. Os sem-terra, ongs e cidadania: a sociedade civil brasileira na era da globalização. 2. ed. São Paulo: Cortez, 2000.

Educação não-formal: cultura política. 2. ed. São Paulo:

Cortez, 2001.

Educação não-formal, participação da sociedade civil e estruturas colegiadas nas escolas. Ensaio - Avaliação e Políticas Públicas em Educação, Rio de Janeiro, v. 14, n. 50, p.27-38, 2006.

. Movimentos sociais: espaços de educação não-formal da sociedade civil. Araucárias, Palmas, PR, v. 3, n. 3, 2004.

HALL, Stuart. A centralidade da cultura: notas sobre as revoluções culturais no nosso tempo. Educação e Realidade, Porto Alegre, v.22, n. 2, p. 15-46, jul/dez, 1997.

Da diáspora: identidades e mediações culturais. Tradução de Adelaine La Guardia Resende et al. Belo Horizonte: Ed. UFMG, 2003.

HAMPATÉ BÂ, Amadou. A tradição viva. In: KI-ZERBO, Joseph (Org.). História geral da África. Tradução de Beatriz Turquetti et al. São Paulo: Ática, 1982. 
PACHECO, Líllian. Pedagogia Griô: a reinvenção da roda da vida. Lençóis, BA.: [s.n.], 2006.

RELATÓRIO da ONG Grãos de Luz e Griô, 2002. [S.1, 2003]

SCHERER-WARREN, I. ONGs na América Latina: trajetória e perfil. In: Meio ambiente, desenvolvimento e cidadania. 2. ed. São Paulo: Cortez; Florianópolis; Universidade Federal de Santa Catarina, 1998.

SIMSON, Olga R. M. von et al. Introdução. In: SIMSON, O. R. M. von et al. (Org). Educação não-formal: cenários da criação. Campinas, SP: Ed. da UNICAMP, 2001. 